\title{
DIVERSIDADE LINGUÍSTICA E A NOÇÃO DE ADEQUAÇÃO APLICADA AO ENSINO DA ESCRITA NO PROCESSO DE ALFABETIZAÇÃO
}

\section{Language diversity and the concept of fitness applied to writing teaching in the literacy process}

\author{
Geiza Gimenes Saraiva - UNIFIMES/UNEMAT/Brasil \\ Stefânia Nunes Sousa - UNIFIMES/Brasil
}

\begin{abstract}
RESUMO: Esta pesquisa teve como objetivo estudar os reflexos da noção de adequação no ensino da escrita, durante o processo de alfabetização. Para isso, buscou i) levantar a noção de adequação nos PCNs de Língua Portuguesa; ii) relacionar a noção de adequação com o fenômeno da variação linguística; e iii) discutir a escrita no processo de alfabetização na sua relação com o letramento. Para tanto, adotou a pesquisa bibliográfica, sob a forma de estudo bibliográfico. Os resultados demonstraram que a escrita não deve estar vinculada à noção de adequação, uma vez que a escrita é heterogênea, assim como a linguagem, de modo que reflete os usos que o falante faz da língua nas suas distintas realizações. Logo priorizar uma única variedade linguística para atender às exigências fundadas na variedade culta da língua é desconsiderar as práticas sociais de leitura e escrita que a criança leva para escola, além de negligenciar a diversidade linguística que se vivencia nesse espaço, lugar fundamentalmente plural. Assim, adequar é discriminar, ignorar a pluralidade social, cultural e linguística. É, portanto, excluir.
\end{abstract}

Palavras-chave: Escrita. Alfabetização. Adequação. Heterogeneidade. Variação linguística.

ABSTRACT: This research aimed to study the reflexes of the notion of adequacy in the teaching of writing, during the literacy process. To this end, it sought to (i) raise the notion of adequacy in Portuguese-speaking PCNs; ii) relate the notion of adequacy with the phenomenon of linguistic variation; and iii) discuss writing in the literacy process in relation to literacy. To this end, it adopted bibliographic research, in the form of bibliographic study. The results showed that the writing should not be linked to the notion of adequacy, since the writing is heterogeneous, as well as the language, so that it reflects the uses that the speaker makes of the language in its different realizations. Therefore, to prioritize a single linguistic variety to meet the demands based on the cultured language variety is to disregard the social reading and writing practices that the child takes to school, besides neglecting the linguistic diversity that is lived in this space, a fundamentally plural place. Thus, to adapt is to discriminate, to ignore social, cultural and linguistic plurality. It is therefore exclude.

Keywords: Writing. Literacy. Adequacy. Heterogeneity. Linguistic Variation.

\section{INTRODUÇÃO}

Educação, Psicologia e Interfaces, Volume 3, Número 3, p. 19-34, Setembro/Dezembro, 2019.

ISSN: 2594-5343. DOI: https://doi.org/10.37444/issn-2594-5343.v3i3.168 
Este trabalho teve como objetivo estudar os reflexos da noção de adequação no ensino da escrita, no contexto da alfabetização. Para isso, buscou i) levantar a noção de adequação nos PCNs de Língua Portuguesa; ii) relacionar a noção de adequação com o fenômeno da variação linguística; e iii) discutir a escrita no processo de alfabetização na sua relação com o letramento.

Para fundamentar a discussão proposta, dialogamos com Soares $(2004 ; 2019)$, Soares e Batista (2005), Cagliari (2010a; 2010b), Corrêa (2010), entre outros, porque tais pesquisadores entendem a alfabetização como processo, não como produto. Nesse sentido, separamos, por um momento, a concepção de alfabetização de letramento, para destacar que alfabetização compreende o ensino das habilidades de leitura e escrita e, desse modo, dizer que nosso foco foi exatamente a escrita, a fim de observar as muitas questões que se colocam em jogo nesse processo, as quais vão além da relação entre grafema e fonema.

Para alcançar os objetivos propostos, inserimos este trabalho na pesquisa bibliográfica com análise documental. E, a partir do estudo bibliográfico, buscamos levantar os diferentes pontos de vista sobre o ensino da escrita. Em seguida, procuramos apontar convergências ou divergências em torno do ensino da escrita e sua relação com a noção de adequação.

Como nosso foco era o ensino da escrita para tratar os reflexos da noção de "adequação" nesse processo, acreditamos na importância de percorrer o campo da alfabetização, como entendida nos documentos oficiais, e relacioná-lo aos apontamentos dos pesquisadores com os quais dialogamos.

Nesses termos, primeiramente, apresentamos o percurso metodológico escolhido por nós para refletir as questões propostas. Na sequência, discorremos sobre alfabetização, a partir de Soares e Cagliari, e apresentamos a noção de alfabetização presente nos PCNs e na BNCC. Também pontuamos a noção de "adequação" e seus desdobramentos no processo de ensino e aprendizagem da escrita, entendendo esta última como um processo. Além disso, apresentamos a relação entre alfabetização e letramento, bem como discutimos a heterogeneidade na escrita e sua relação com o fenômeno da variação.

Nossas reflexões apontaram as implicações e reflexos da noção de adequação aplicada no ensino da escrita, alertando que a escrita não deve estar vinculada a esta 
Diversidade linguística e a noção de adequação aplicada ao ensino da escrita no processo de alfabetização

noção, uma vez que ela é heterogênea, assim como a linguagem, de modo que reflete os usos que o falante faz da língua nas suas distintas realizações. Logo priorizar uma única variedade linguística (a adequação) para atender às exigências fundadas na variedade culta da língua é desconsiderar as práticas sociais de leitura e escrita que a criança leva para escola, além de negligenciar a diversidade linguística que se vivencia nesse espaço, lugar fundamentalmente plural. Assim, adequar é discriminar, ignorar a pluralidade social, cultural e linguística. É, portanto, excluir.

\section{MATERIAL E MÉTODO}

Para atender aos objetivos propostos neste estudo, adotou-se a pesquisa bibliográfica, a fim de levantar as distintas contribuições científicas acerca do tema desta pesquisa. As etapas seguidas foram: i) levantamento bibliográfico; ii) seleção da bibliografia; iii) leitura analítica e comparação dos dados e iv) apresentação dos resultados.

$\mathrm{Na}$ pesquisa bibliográfica, a coleta de dados não é direta, ou seja, com observações, entrevistas, questionários, etc, entretanto, isso não inviabiliza a construção de um trabalho inédito, já que tal pesquisa permite rever, reanalisar apontamentos teóricos, no sentido de ressignificar possíveis leituras, ou mesmo apresentando novos olhares acerca de um determinado tema (MARTINS, 2015).

A pesquisa bibliográfica, segundo Vergara, (2016) consiste na realização de um estudo sistematizado em bancos de dados, livros, revistas especializadas, jornais, ou qualquer outro material disponível ao público de modo geral, permitindo, desse modo, a estruturação de um trabalho científico, como, por exemplo, o que se apresenta neste texto.

\section{PROCESSOS ENTRELAÇADOS}

\subsection{A alfabetização}

Para se alfabetizar, é preciso ensinar o aluno a decifrar a palavra escrita, pois é a partir do conhecimento da palavra escrita que o aluno é capaz de viver novas experiências, criar suas próprias experiências de escrita. O segredo de decifrar a escrita está na leitura,

Educação, Psicologia e Interfaces, Volume 3, Número 3, p. 19-34, Setembro/Dezembro, 2019.

ISSN: 2594-5343. DOI: https://doi.org/10.37444/issn-2594-5343.v3i3.168 
mas, para isso, o aluno precisa "saber como os sistemas de escrita funcionam e quais seus usos" (CAGLIARI, 2010b, p. 99). Não se trata se um ato mecânico.

Soares e Batista (2005) pontuam que a alfabetização diz respeito à aquisição de uma tecnologia da linguagem humana, ou seja, a escrita alfabético-ortográfica, a qual implica um conjunto de conhecimentos e procedimentos para representar esse sistema linguístico e envolve também as capacidades motoras e cognitivas da criança nesse processo.

No processo de alfabetização, segundo os autores, o aluno vai se conscientizando pouco a pouco que nosso sistema de escrita alfabético-ortográfica (letras e grafemas) representa uma das partes do signo linguístico, o significante (imagem acústica), portanto temos a representação, na escrita, dos sons da língua, e não de seu significado, como acontece no sistema ideográfico. Além disso,

Alfabetização não é uma questão de método. O grande equívoco na área é que, historicamente, sempre se considerou que alfabetização era uma questão de método. Isso é um equívoco porque nenhuma outra disciplina -geografia, história, ciências e matemática- trata de um só método (SOARES, 2019, online).

Para que a alfabetização ocorra de modo eficaz, o alfabetizador deve compreender como a criança aprende, pois só assim será capaz de mediar esse processo em construção, a experiência que a criança desenvolve com a linguagem. Logo, ter um método de alfabetização, seja ele sintético ou analítico, não é garantia de sucesso no processo de alfabetização, pois esse processo envolve conhecimento de psicologia, psicogenética, linguística, fonologia, etc, e, infelizmente, “[...] professores, nos cursos de pedagogia não discutem os fundamentos da alfabetização, não discutem como a criança aprende e, portanto, como se deve ensinar", segundo Soares (2019, online). Para a pesquisadora, os grandes entraves na alfabetização estão relacionados à formação do professor, por isso a autora diz que alfabetizar "não é uma questão de método", mas de conhecer o sujeito cognoscente.

Se alfabetizar vai além dos métodos, porque requer do alfabetizador conhecer como aprende o sujeito centro desse processo, bem como ser conhecedor de teorias que se integrem a sua prática docente, tanto os PCNs (Parâmetros Curriculares Nacionais) 
quanto a BNNC (Base Nacional Curricular Comum) parecem caminhar na contramão desse processo, ao nortear o ensino brasileiro.

Nos PCNs de língua portuguesa, encontramos a seguinte definição para alfabetização: “[...] aquisição da escrita alfabética [...]. Para aprender a ler e a escrever é preciso pensar sobre a escrita, pensar sobre o que a escrita representa e como ela representa graficamente a linguagem" (BRASIL, 1997, p. 23; 51).

Já na BNCC, a alfabetização é assim definida:

[...] conhecer a 'mecânica' ou o funcionamento da escrita alfabética para ler e escrever significa, principalmente, perceber as relações bastante complexas que se estabelecem entre os sons da fala (fonemas) e as letras da escrita (grafemas), o que envolve consciência fonológica da linguagem: perceber seus sons, como se separam e se juntam em novas palavras etc. (BRASIL, 2017, p. 90).

Quando comparamos os dois documentos, verificamos que a alfabetização se resume às propriedades fonológicas da língua, à relação entre fonema e grafema. Além disso, a alfabetização, como proposta na BNCC, é um ato mecânico desvinculado das questões culturais e das práticas sociais. Tomada em sua face "mecânica", a alfabetização não promoveria a compreensão de como a criança aprende. É mais uma questão de método, novamente, o que nos leva à apresentação da relação entre alfabetização e letramento.

\section{2 Alfabetização e letramento}

Soares (2004), em seu texto "Alfabetização e Letramento: caminhos e descaminhos", pontua alguns desencontros presentes nas práticas de alfabetização e letramento. Segundo a autora, alfabetização e letramento são processos, do ponto de vista conceitual, distintos, porém interdependentes.

A inserção da concepção de letramento na escola provocou um descompasso da especificidade da alfabetização. Para Soares (2004),

alfabetização - entendida como a aquisição do sistema convencional de escrita - distingue-se de letramento - entendido como o desenvolvimento de comportamentos e habilidades de uso competente da leitura e da escrita em práticas sociais: distinguem-se tanto em

Educação, Psicologia e Interfaces, Volume 3, Número 3, p. 19-34, Setembro/Dezembro, 2019.

ISSN: 2594-5343. DOI: https://doi.org/10.37444/issn-2594-5343.v3i3.168 
relação aos objetos de conhecimento quanto em relação aos processos cognitivos e linguísticos de aprendizagem e, portanto, também de ensino desses diferentes objetos (SOARES, 2004, p. 97).

A aquisição do sistema convencional de escrita é fundamental para que o aluno amplie suas experiências de práticas sociais de leitura. Alfabetizar de modo produtivo é levar o aluno à aquisição da tecnologia da escrita, mas fazendo isso num contexto de práticas sociais de leitura e escrita que sejam significativas para o aluno, ou seja, por meio de atividades de letramento, caso contrário o aluno verá a alfabetização como um ato mecânico e "sem graça", porque não terá significado para ele, ou como diz Soares (2004): "uma alternância entre métodos sintéticos e métodos analíticos", desvinculados da reflexão de quem é o sujeito cognoscente.

Nesse sentido, o processo de aquisição da escrita deve ser fundamentado em práticas reais de leitura e não em textos, sentenças, palavras que não refletem o dia a dia do aluno. Isso não passa de uma prática artificial no ensino da escrita, porque não desperta no aluno curiosidade por esse novo mundo da escrita. Por outro lado, quando as atividades de ensino da escrita estão vinculadas a sua realidade, o aluno se aproxima daquilo que é proposto a ele, porque as atividades refletem o mundo de leitura e escrita no qual ele está inserido.

Talvez por isso temos sempre fracassado nesse ensino e aprendizagem; o caminho para esse ensino e aprendizagem é a articulação de conhecimentos e metodologias fundamentados em diferentes ciências e sua tradução em uma prática docente que integre as várias facetas, articulando a aquisição do sistema de escrita, que é favorecida por ensino direto, explícito e ordenado, aqui compreendido como sendo o processo de alfabetização, com o desenvolvimento de habilidades e comportamentos de uso competente da língua escrita nas práticas sociais de leitura e de escrita, aqui compreendido como sendo o processo de letramento (SOARES, 2004, p. 100).

Como observa Soares, não se deve priorizar uma outra faceta no ensino da escrita, mas considerar as especificidades tanto da alfabetização quanto do letramento na prática produtiva desse ensino.

A aquisição da escrita em processo de alfabetização ou de letramento, ou mesmo alfabetizar letrando traz em si outras reflexões, porque a escrita não é homogênea, como querem fazer crer alguns, mas é atravessada de uma série de outras questões que deve se considerar nesse ensino. 
Diversidade linguística e a noção de adequação aplicada ao ensino da escrita no processo de alfabetização

\subsection{A escrita}

A aquisição do sistema de escrita no processo de alfabetização está intimamente relacionada com a noção de adequação, pois, geralmente, muito se ouve dizer que o aluno precisa adequar a sua escrita, conforme as situações de comunicação. Esse discurso traz em si implicações sérias, que precisam ser discutidas, de modo que todo alfabetizador deve ter consciência do que está por trás de sua prática pedagógica, o que nos leva a pontuar os desdobramentos da noção de adequação no ensino dessa habilidade e sua estreita relação com a heterogeneidade constitutiva da linguagem, a partir do diálogo com Corrêa (2010).

\subsection{A noção de adequação e a heterogeneidade na/da escrita}

Quando a criança é convidada a passar da fala para escrita, essa passagem em si mesma já demonstra que a escrita não é homogênea como se procura fazer crer, muitas vezes, na escola. A relação entre grafema e fonema comprova a existência de duas tecnologias que se entrelaçam, isto é, a fala e a escrita, de modo que na escrita os traços da fala se fazem presentes nesse processo de aprendizagem da criança, em que ela busca apoiar sua escrita na sua própria variedade linguística, que lhe é familiar e, geralmente, diferente da variedade cobrada na escola.

Procurando encaminhar a criança para a ortografia da língua, a escola se esquece que, nesse percurso, entre a fala e a ortografia, existem as reflexões linguísticas da criança, em que sua escrita é amparada numa de suas variantes linguísticas, pois é assim que a criança aprende. Primeiro, passa da fala para uma escrita apoiada em sua variante linguística, e só depois chega ou chegará ao padrão ortográfico da língua.

Infelizmente, a escola quer que a criança domine rapidamente os padrões ortográficos da língua, e é aí que muitos equívocos acontecem, quando se cobra da criança apenas uma das variedades da língua com o objetivo de adequá-la a esse padrão ou variedade exigida na escola.

A noção de adequação, presente na escola, faz parte das reflexões dos estudos de Corrêa (2010), contexto em que o autor apresenta os desdobramentos dessa postura da instituição escolar frente à aquisição da escrita pela criança. Para o pesquisador, a escola

Educação, Psicologia e Interfaces, Volume 3, Número 3, p. 19-34, Setembro/Dezembro, 2019. 
deve compreender que a escrita não é homogênea, já que é possível reconhecer pelo menos três formas de heterogeneidade da escrita:

1) por meio de aspectos da representação gráfica, já que, no processo da escrita, o escrevente oscila entre a tentativa de representação de características fonético-fonológicas (segmentais e/ou prosódicas) detectadas em sua variedade lingüística falada e a convenção ortográfica institucionalizada, esta última baseada, como se sabe, na variedade submetida à normalização e posterior codificação;

(2) pela referência à heterogeneidade da língua, pois, se a admitimos como estruturalmente marcada no sistema - contribuição trazida pela sociolingüística - não há razão para não admiti-la na escrita, com a condição de que esta última seja vista como um modo de enunciação e não apenas como uma tecnologia;

(3) pela circulação dialógica que o escrevente faz ao produzir o texto escrito, uma vez que [...] o escrevente lida: (a) com o que imagina ser a representação termo a termo da fala pela escrita; (b) com o que imagina ser - a partir de suas experiências com a escrita e com a própria visão escolar sobre a escrita - o código escrito institucionalizado; e, finalmente, (c) com o que imagina ser a relação apropriada com a exterioridade que constitui o seu texto: outros textos, a própria língua, outros registros, outros enunciadores, o próprio leitor (CORRÊA, 2010, p. 270-271).

Pelo exposto, o pesquisador chama a atenção para o fato de que a criança, na escola, é levada a usar a linguagem de maneira eficaz, adequada às diversas situações de comunicação. Entretanto, o conceito de adequação carrega em si alguns desdobramentos que merecem ser destacados para se entender o que é adequar a linguagem às diversas situações.

Se a escrita é heterogênea, é preciso considerar no processo de sua aquisição as reflexões que o aprendiz faz nessa aprendizagem e refletir com cuidado como conduzi-lo nessas situações, pois, muitas vezes, na ânsia de buscar o padrão culto da língua, muitos equívocos são cometidos, desprezando-se a riqueza da linguagem e a diversidade linguística e cultural existente no contexto escolar, em nome de uma forma de expressão linguística.

Segundo Corrêa (2010), em nome da escrita padrão, homogeneizada, os alunos são levados, na produção de seus textos, por exemplo, à recusa de qualquer forma linguística que não represente o estilo ortográfico oficial, apagando-se as marcas desse aluno no texto, seus regionalismos, enfim, toda forma que vá contra o padrão instituído pela escola. 
Barzotto (2004) pensa a questão do tratamento dado à variação linguística tanto por linguísticas quanto por pedagogos, no que diz respeito ao "valorizar", "respeitar" e "adequar", posições enunciativas que, segundo o pesquisador, muito dizem sobre as práticas adotadas por aqueles que trabalham e pesquisam o assunto. Para Barzotto, três questões se colocam sobre a situação:

1) Quanto ao "respeitar": "a insistência em reafirmar o dever de respeitar, (sic) mais parece uma aceitação pacífica da existência de desrespeito do que uma resistência ativa"

(2) Sobre "valorizar": conduz-se para direção em que "o sujeito de valorizar [se coloque] numa posição tal que lhe permita dar ou aumentar o valor da variedade em questão" (mesmo que esse posicionamento busque respaldo numa imposição de uma instância maior: "é a sociedade que não valoriza e por isso pessoas conscientes teriam de fazê-1o"); enunciados que produzem, parece não se ter dado conta de que a adequação de registro à situação de uso não vem imposta de fora para dentro, mas depende em parte da presença ativa dos interlocutores" (3) No que diz respeito ao "adequar": diria-se que há a segregação de algumas variedades, quando se define a especificidade de seus lugares de pertencimento ou seu "reduto", visto que observa-se "um cerceamento sobre o uso de variedades que não gozem de prestígio na sociedade" (BARZOTTO, 2004, p. 94-95).

Para o estudioso, a insistência em se respeitar determinada variedade linguística em detrimento de outra instala um processo de hierarquização entre as variedades linguísticas que circulam na sociedade. Essa hierarquização leva, consequentemente, à exclusão de uma forma em prol de outra mais respeitada, mais prestigiada.

Outro aspecto pontuado por Barzotto é que, ao se valorizar uma variedade linguística, além da hierarquização que se instala nessa postura, diante das variedades, a escola produz uma gradação de valores entre as variedades linguísticas, do tipo: a variedade linguística do aluno é “ótima”, mas lá no grupo familiar dele. Na escola, valoriza-se, prioriza-se a forma padrão da língua. Nesse sentido,

[...] quem se propõe a valorizar, precisa assumir uma posição de onde possa fazê-lo, reconhecendo, em primeiro lugar uma falta de valor na variedade praticada pelo outro e elevando esse valor apoiando-se em sua capacidade de reconhecer essa falta, conferida pela imagem que faz de si. Isso é indicador de discriminação. Portanto, propor-se a valorizar a variedade lingüística praticada por outro falante exige reconhecer que a variedade do outro está desprovida de algum valor. [...] Exigir que outro valorize, como se faz em recomendações para o

Educação, Psicologia e Interfaces, Volume 3, Número 3, p. 19-34, Setembro/Dezembro, 2019.

ISSN: 2594-5343. DOI: https://doi.org/10.37444/issn-2594-5343.v3i3.168 
ensino, é ainda duplamente discriminatório, pois se coloca em lugar de maior prestígio, tanto com relação a uma variedade [que se] julga carecer de valorização, quanto com relação àquele que supostamente não sabe que tal variedade precisa ser valorizada (BARZOTTO, 2004, p. 94-95, grifos nossos).

Quanto à adequação da variedade linguística do aluno à variedade culta da língua, ao padrão linguístico proposto pela escola, a pesquisa de Barzotto aponta o cerceamento, ou silenciamento da diversidade linguística presente no contexto escolar, em função de uma única variedade linguística, pois

[...] aquele que se propõe a ensinar o uso adequado da variedade também se coloca em um lugar tal de onde possa reconhecer a inadequação do outro e, deste lugar, reforça a idéia de inadequação no falante que não usa a variedade de prestígio. [...] O trabalho pedagógico que se faz a partir desta vertente geralmente faz o movimento de partir da variedade de menor prestígio em direção à de maior prestígio. É aquele que é julgado inadequado que vai ser convocado a adequar-se, o que pode ser bastante discriminatório [...] (BARZOTTO, 2004, p. 95).

Como forma de evitar posturas discriminatórias no ensino da escrita, já que esta é heterogênea na sua constituição, Barzotto recomenda a utilização do verbo "incorporar" na prática e nas posturas enunciativas daqueles que estão envolvidos nesse processo, pois tal verbo representa agregar, assimilar as diferenças sem negligenciar as demais realidades linguísticas, mas, ao contrário, enriquecê-las a partir de sua convivência mútua, propiciando a expressão da pluralidade e da diversidade cultural e linguística no aprendizado da escrita dentro e fora da escola.

\subsection{Indagações}

Diante do exposto, os seguintes questionamentos surgem: O que é escrita adequada, proposta nos diferentes documentos que norteiam o processo de ensinoaprendizagem? Como trabalhar essa escrita adequada, já que a escrita é heterogênea? Essas são questões que buscamos pontuar nos resultados deste estudo.

Como se viu, a escrita é heterogênea, assim como o é a própria língua, pois reflete as experiências linguísticas dos sujeitos que a utilizam. Desse modo, a criança, quando chega à escola, já traz consigo uma experiência linguística, a qual não deve ser desconsiderada, mas incorporada, pela escola, ao processo de aquisição da escrita enquanto uma habilidade necessária para ampliar as experiências desse sujeito.

Educação, Psicologia e Interfaces, Volume 3, Número 3, p. 19-34, Setembro/Dezembro, 2019.

ISSN: 2594-5343. DOI: https://doi.org/10.37444/issn-2594-5343.v3i3.168 
Diversidade linguística e a noção de adequação aplicada ao ensino da escrita no processo de alfabetização

Cagliari (2010a; 2010b) chama a atenção para o fato de que, na alfabetização, a criança deve ser conduzida para o aprendizado da escrita (decifração), em que o objetivo é a leitura, mas este aprendizado é uma das etapas para que a criança construa sua própria escrita a partir da aquisição desta habilidade, ou seja, que ela possa expressar sua criatividade com liberdade, contexto em que o professor é um orientador, um mediador, não um ditador de padrões pré-estabelecidos.

Para o autor, na alfabetização, é preciso ter claro também que a escrita não é o espelho da fala, de modo que o alfabetizador deve ser consciente de que, entre a escrita e a fala, há uma complexidade de fenômenos que precisam ser considerados, como, por exemplo, a transposição de palavras como "apto”, “fixo", "táxi”, uma vez que não há uma correspondência sincronizada entre fonemas e grafemas nesses casos, o que requer o respeito à maturidade linguística da criança no processo de aquisição da escrita dessas formas.

Soares e Batista (2005), ao pontuarem que a alfabetização é o espaço em que a criança aprende a escrita alfabética, colocam em discussão o papel da escola nesse processo, já que na passagem da fala para a escrita esperada pela escola existem as experiências linguísticas da criança, ou seja, entre a fala e a orografia da língua, objetivo maior da instituição escolar, há uma outra etapa que a antecede:

\section{Fala $\rightarrow$ variedade linguística do falante $\rightarrow$ ortografia}

Como exposto, a criança não chega vazia à escola, pois ela já possui experiências linguísticas, as quais devem ser respeitadas e incorporadas no processo de alfabetização, particularmente no ensino da escrita. Na ânsia de que a criança atinja a forma ortográfica da língua, muitos alfabetizadores acabam atropelando esse processo, por não entender ou mesmo não respeitar tanto a diversidade linguística quanto a diversidade cultural existente em uma sala de aula.

A criança escreve, primeiramente, na sua variedade linguística, ou seja, reflete em sua escrita as experiências linguísticas que ela traz de seu contexto social, de seu grupo, as heranças familiares. Assim, uma criança da região do nordeste, por exemplo, vai produzir na escrita formas como "mélaum”, pois em muitas regiões do nordeste o som de

Educação, Psicologia e Interfaces, Volume 3, Número 3, p. 19-34, Setembro/Dezembro, 2019.

ISSN: 2594-5343. DOI: https://doi.org/10.37444/issn-2594-5343.v3i3.168 
"e" nesta palavra é aberto, diferentemente da pronúncia desta mesma palavra no Estado de Goiás, em que a pronúncia é com "e" fechado.

Exemplo como o citado demonstra as reflexões que a criança faz na passagem da fala para a escrita, uma vez que ela não representará diretamente a forma da ortografia oficial de sua língua, como costumeiramente se espera dela na escola, mas, antes, escreverá, segundo sua variedade linguística. Desse modo, exigir da criança que ela se adeque ao padrão oficial de escrita da língua portuguesa é desprestigiar ou ignorar sua variedade linguística e definir como "erro" qualquer forma que não venha ao encontro da ortografia.

Situações como essas, segundo Soares (2019), ocorrem porque o alfabetizador não compreende como a criança aprende, logo, não consegue mediar esse processo de forma coerente, de modo que os desdobramentos dessa falta de compreensão produzem posturas como: “meu aluno não sabe escrever”, "ele erra tudo que eu falo", "troca tudo de lugar", etc. Para a pesquisadora, na alfabetização, a questão não é apenas a escolha de um método, já que esse processo envolve conhecimento de psicologia, psicogenética, linguística, fonologia, etc, e, infelizmente, “[...] professores, nos cursos de pedagogia não discutem os fundamentos da alfabetização, não discutem como a criança aprende e, portanto, como se deve ensinar", segundo Soares (2019, online). Os grandes entraves na alfabetização estão relacionados à formação do professor, por isso a autora diz que alfabetizar "não é uma questão de método", mas de conhecer o sujeito cognoscente, suas reflexões, suas experiências linguísticas antes de chegar a escola, buscar compreender as reflexões que ele faz ao escrever uma determinada palavra que ainda não está segundo a ortografia, de acordo com a autora.

É por razões como as apresentadas que a pesquisadora chama a atenção para o fato de que a escrita não e homogênea, de modo que sua aquisição em processo de alfabetização ou de letramento, ou mesmo alfabetizar letrando traz em si outras reflexões que devem ser discutidas constantemente pelos responsáveis por mediar esse processo, já que não existem caminhos prontos e acabados, o que requer discutir conceitos como os apresentados na BNCC, documento mais recente de norteamento da educação básica, no qual a alfabetização é um ato mecânico desvinculado das questões culturais e das práticas sociais. Tomada em sua face "mecânica", a alfabetização não promoveria a compreensão de como a criança aprende.

Educação, Psicologia e Interfaces, Volume 3, Número 3, p. 19-34, Setembro/Dezembro, 2019.

ISSN: 2594-5343. DOI: https://doi.org/10.37444/issn-2594-5343.v3i3.168 
De modo geral, segundo Corrêa (2010), a aquisição da escrita está vinculada à adequação da escrita da criança a um sistema específico ou a uma variedade linguística particular, geralmente a variedade culta da língua. Assim, a escola persiste nesse objetivo, buscando levar a criança à aquisição dessa forma "ideal".

Para o autor, essa postura tem implicações, uma vez que a escrita não é homogênea, já que a "simples" relação entre grafemas e fonemas já comprovam isso. E mais, é inadmissível negar a heterogeneidade linguística, quando diferentes estudos a comprovam, logo ignorar isso é negligenciar o ensino da escrita no contexto escolar, assim como é negligência desconsiderar as reflexões que a criança faz na aquisição dessa face da linguagem.

Por essa razão, Barzotto (2004) faz severas críticas a práticas enunciativas em que linguistas e pedagogos propagam a necessidade de "valorizar", "respeitar" e "adequar" as variedades linguísticas, pois, segundo o pesquisador, a insistência em se respeitar determinada variedade linguística em detrimento de outra instala um processo de hierarquização entre as variedades linguísticas que circulam na sociedade. Essa hierarquização leva, consequentemente, à exclusão de uma forma em prol de outra mais respeitada, mais prestigiada.

No que diz respeito a valorizar uma variedade linguística, além da hierarquização que se instala nessa postura, diante das variedades, a escola produz uma gradação de valores entre as variedades linguísticas, do tipo: a variedade linguística do aluno é “ótima”, mas lá no grupo familiar dele. Na escola, valoriza-se, prioriza-se a forma padrão da língua.

Quanto à adequação da variedade linguística do aluno à variedade culta da língua, ao padrão linguístico proposto pela escola, Barzotto destaca o cerceamento, ou silenciamento da diversidade linguística presente no contexto escolar, em função de uma única variedade linguística: a variedade culta.

Para o autor, a eficácia e produtividade no trabalho com o fenômeno da variação linguística no contexto escolar deve residir na prática enunciativa "incorporar", já que este verbo traz em si o sentido de agregar, assimilar as diferenças sem negligenciar as

Educação, Psicologia e Interfaces, Volume 3, Número 3, p. 19-34, Setembro/Dezembro, 2019.

ISSN: 2594-5343. DOI: https://doi.org/10.37444/issn-2594-5343.v3i3.168 
demais realidades linguísticas, mas, ao contrário, enriquecê-las a partir de sua convivência mútua.

Diante do exposto, acreditamos na necessidade de se compreender como o aluno aprende para que se possa incorporar com responsabilidade as diferentes formas e práticas sociais de leitura e escrita que ele leva para a escola, e ter a consciência de que a escrita é uma das faces da linguagem, ela é, portanto, variável, assim como é a língua. Assim, escrever não é apenas uma escolha de método que se uniformiza numa realidade que é sempre plural: a sala de aula.

\section{CONSIDERAÇÕES FINAIS}

Os diferentes estudiosos com os quais dialogamos são unânimes em apontar que a escrita não é homogênea, de modo que seu ensino na alfabetização não deve se reduzir à adequação a uma única forma, ou a uma única variedade linguística.

Para que tal equívoco não ocorra, é preciso considerar a diversidade linguística e cultural presente no contexto escolar, incorporar a variedade linguística do aluno a este contexto, de modo que se promova a convivência mútua entre as diferentes variedades linguísticas e se minimize os impactos da hierarquização ou exclusão de uma variedade linguística em prol de outra, geralmente prestigiada, já que tal conduta produz a exclusão linguística, mas também a exclusão social do aluno no contexto escolar.

Todas as variedades linguísticas são adequadas, porque comunicam, logo é essa riqueza, essa diversidade que garante a pluralidade social que o aluno leva para o contexto escolar, tornando esse espaço lugar de convivência de práticas sociais distintas, razão pela qual a diversidade deve ser trabalhada a partir do que Soares propõe em seus estudos: "alfabetizar letrando", respeitando todas as experiências de leitura e escrita que chegam à escola, não silenciá-las, sufocá-las em nome de uma forma homogeneizada de ensino da escrita, reduzindo o ensino da escrita a questões de adequação a um contexto "x".

\section{REFERÊNCIAS BIBLIOGRÁFICAS}

BARZOTTO, V. H. Nem respeitar, nem valorizar, nem adequar as variedades linguísticas. Cáceres, Revista Ecos, n. 2, jul, p. 93-96, 2004. Disponível em: http://www.unemat.br/revistas/ecos/docs/v_02/93_Pag_Revista_Ecos_V-02_N-02_A2004.pdf BARZOTTO. Acesso em: 15 jul. 2019. 
Diversidade linguística e a noção de adequação aplicada ao ensino da escrita no processo de alfabetização

BRASIL. Base Nacional Comum Curricular- BNCC. Disponível em:

http://basenacionalcomum.mec.gov.br/images/BNCC_EI_EF_110518_versaofinal_site. pdf. Acesso em: 03 mai. 2019.

BRASIL. Secretaria de Educação Fundamental. Parâmetros curriculares nacionais: língua portuguesa /Secretaria de Educação Fundamental. Brasília:1997.144p.

CAGLIARI, L. C. Alfabetização e linguística. São Paulo: Scipione, 2010a.

CAGLIARI, L. C. Alfabetizando sem o bá-be-bi-bó-bu. São Paulo: Scipione, 2010 b.

CORRÊA, M. L. G. Heterogeneidade da escrita: a novidade da adequação e a experiência do acontecimento. São Paulo, Filologia e Linguística Portuguesa, n. 8, p. 269-286, 2010. Disponível em: https://doi.org/10.11606/issn.2176-9419.v0i8p269-286. Acesso em: 12 março 2019.

MARTINS, R. Metodologia científica. Rondonópolis: 2015. (material cedido)

SOARES, M. Vivi Estado Novo e ditadura, mas nunca vi período tão assustador. 2019. Disponível em: https://www1.folha.uol.com.br/educacao/2019/01/vivi-estadonovo-e-ditadura-mas-nunca-vi-periodo-tao-assustador-diz-referencia-emalfabetizacao.shtml. Acesso em: 23 abr. 2019.

SOARES, M. Alfabetização e Letramento: caminhos e descaminhos. Revista Pátio, n. 29. fev, 2004.

SOARES, M.; BATISTA, A. A. G. Alfabetização e letramento: caderno do professor. Belo Horizonte: Ceale/FaE/ UFMG, 2005. Disponível em:

http://ceale.fae.ufmg.br/app/webroot/files/uploads/Col.\%20Alfabetiza\%C3\%A7\%C3\% A3o\%20e\%20Letramento/Col\%20Alf.Let.\%2001\%20Alfabetizacao_Letramento.pdf. Acesso em: 24 abr. 2019.

VERGARA, S. C. Projetos e relatórios de pesquisa em Administração. São Paulo: Atlas, 2016.

\section{Credenciais da/os autora/es}

SARAIVA, Geiza Gimenes. Professora da Unifimes (Centro Universitário de Mineiros/GO) e da Universidade do Estado de Mato Grosso (UNEMAT). Graduada em Licenciatura Plena em Letras na Universidade Federal de Mato Grosso (UFMT), Mestre em Letras: estudos linguísticos na Universidade Federal de Mato Grosso do Sul (UFMS), Doutora em Linguística e Língua Portuguesa na Universidade Estadual Paulista "Júlio de Mesquita Filho"(UNESP). E-mail: geizaggimenes@ gmail.com

Educação, Psicologia e Interfaces, Volume 3, Número 3, p. 19-34, Setembro/Dezembro, 2019.

ISSN: 2594-5343. DOI: https://doi.org/10.37444/issn-2594-5343.v3i3.168 
SOUSA, Stefânia Nunes de. Graduada em Pedagogia pelo Unifimes (Centro Universitário de Mineiros/GO). E-mail: nunesstefania@gmail.com

Endereço para correspondência: Geiza Gimenes Saraiva. Rua João Segundo, n.1349, casa 09, Bairro: Atlântico, CEP:78780-000, Alto Araguaia-Mato Grosso. E-mail:

geizaggimenes@gmail.com

Como citar este artigo (Formato ABNT): SARAIVA, Geiza Gimenes; SOUSA, Stefânia Nunes de. Diversidade linguística e a noção de adequação aplicada ao ensino da escrita no processo de alfabetização. Educação, Psicologia e Interfaces, v. 3, n. 3, p. 19-34, 2019. DOI: https://doi.org/10.37444/issn-2594-5343.v3i3.168

Recebido: 07/08/2019.

Aceito: 20/11/2019. 